\title{
Leptina: Aspectos Sobre o Balanço Energético, Exercício Físico e Amenorréia do Esforço
}

\begin{abstract}
RESUMO
O presente manuscrito teve por objetivo realizar uma revisão bibliográfica acerca do papel da leptina no balanço energético, no exercício físico e na incidência da amenorréia do esforço. A leptina é um hormônio secretado pelo tecido adiposo, reconhecido principalmente por sua ação adipostática sobre o sistema nervoso central. Esse hormônio sinaliza o hipotálamo a respeito das reservas energéticas, modulando o funcionamento dos eixos hormonais que envolvam o hipotálamo e a hipófise. A leptina tem ainda ações periféricas importantes, incluindo seu papel sobre o tecido ovariano. Os mecanismos de sinalização intracelular desse hormônio foram identificados no hipotálamo, porém em tecidos periféricos há necessidade de maiores investigações. Existe certo consenso de que quando o exercício e a ingestão alimentar são capazes de promover um balanço energético negativo, as concentrações plasmáticas de leptina diminuem, alterando conseqüentemente: a liberação hipotalâmica de GnRH (fator hipotalâmico de liberação de gonadotrofinas); a liberação hipofisária de LH (hormônio luteinizante) e FSH (hormônio folículo-estimulante). Como resultado, há menor liberação de estrógenos ovarianos. Esse processo pode iniciar a chamada amenorréia hipotalâmica funcional, com repercussões na saúde da mulher. Nessa perspectiva, a avaliação do gasto energético e a elaboração de um plano alimentar adequado em atletas são fundamentais. (Arq Bras Endocrinol Metab 2007;51/1:11-24)
\end{abstract}

Descritores: Balanço energético; Leptina; Dieta; Exercício; Amenorréia do esforço

\begin{abstract}
Leptin: Aspects on Energetic Balance, Physical Exercise and Athletic Amenorhea.

The aim of this manuscript was to review the knowledge about leptin, detailing its relationship with energetic intake and physical activity. Leptin is an adipocyte hormone, recognized mainly for its putative role in control of energy expenditure, food intake, body weight and reproductive function. Leptin has still important peripheral actions, including its role on the ovarian tissue. The intracellular signaling mechanisms are recognized in hypothalamus, but in peripheral tissue are not fully understood. The exercise, when practiced by women, if not appropriately planned according to food intake, can modify the leptin release. When energy imbalances induced by exercise and/or deficient food ingestion occurs, low leptin levels are observed, leading to a reduction in GnRH (gonadotropin-release hormone), in LH (luteinizing hormone) and FSH (follicle-stimulating hormone) in pituitary, and consequently a minor release of ovarian estrogens. This process is named hypothalamic amenorrhea, and has repercussions in the woman's health. In this perspective, it is important to emphasize the need to evaluate the energy expenditure from exercise and to formulate adequate alimentary plans to these individuals.
\end{abstract}

(Arq Bras Endocrinol Metab 2007;51/1:11-24)

Keywords: Energetic balance; Leptin; Diet; Physical exercise revisão

\author{
SANDRA MARIA LIMA RIBEIRO \\ ZIRLENE ADRIANA DOS SANTOS \\ RENATA JULIANA DA SILVA \\ ELIANA LOUZADA \\ JOSÉ DONATO JUNIOR \\ JULIO TIRAPEGUI
}

Grupo de Estudos em Nutrição e Atividade Física, Programa de Pós Graduação Stricto Sensu em Educação Física da

Universidade São Judas Tadeu

(SMLR, ZAS, RJS \& EL);

Departamento de Alimentos e Nutrição Experimental da Faculdade de Ciências Farmacêuticas (JT) e Departamento de Anatomia do Laboratório de Neuroanatomia Química (JDJ) da Universidade de São Paulo, SP. Presidente SBEM, Gestão 2005/2006

Recebido em 26/04/06 Aceito em 07/07/06 
$\mathrm{O}$ CICLO MENSTRUAL FEMININO é resultado de um processo regulado ciclicamente por fatores hipotalâmicos, hormônios da adenohipófise e hormônios ovarianos. A ausência ou intervalo superior a noventa dias entre os períodos menstruais caracteriza a amenorréia. Esta disfunção é comum em mulheres atletas, em mulheres submetidas à restrição alimentar crônica e/ou severa, ou ainda outras situações específicas. Na amenorréia, a secreção dos fatores hipofisiotróficos no hipotálamo é alterada, o que conseqüentemente modifica as secreções hipofisárias e ovarianas $(1,2)$.

Alguns hormônios não participam diretamente do eixo reprodutivo, mas têm um papel fundamental na regulação de suas funções. A leptina atua como um sinal hormonal que veicula informação do tecido adiposo para o eixo reprodutivo. Esse hormônio pode constituir um fator decisivo para o início do desenvolvimento puberal, pois existe associação entre concentração de leptina plasmática, o início da puberdade e a menstruação $(3,4)$. A manutenção de uma concentração mínima de leptina parece ser necessária para o funcionamento adequado do sistema reprodutivo na fase adulta. Esses argumentos são reforçados por vários estudos demonstrando distúrbios que levam à amenorréia hipotalâmica funcional decorrentes de uma baixa concentração de leptina, de uma reduzida quantidade de gordura corporal e/ou de uma ingestão energética insuficiente. Além disso, animais e seres humanos deficientes em leptina ou em seu receptor apresentam graves alterações no sistema reprodutivo (5-8).

Buscando melhor compreensão dos mecanismos acima descritos, o presente manuscrito tem por objetivos: identificar os mecanismos de ação da leptina e sua resposta à baixa ingestão energética e ao exercício físico; investigar as alterações no eixo reprodutivo causadas por essas situações; discutir o papel da nutrição adequada na modulação desses processos.

\section{MATERIAIS E MÉTODOS}

O trabalho consistiu de uma revisão da literatura, com consulta às bases de dados MEDLINE, LILACS E PUBMED. O período de consulta foi de 1995 a 2005. A busca foi realizada com as seguintes palavras-chave: reprodução, energia, exercício, leptina e estradiol. Para elucidação de alguns conceitos básicos, também foram consultados alguns livrostexto. Quando foram identificadas nos artigos citações relevantes anteriores ao período consultado, estas também foram obtidas e incluídas.

\section{DESENVOLVIMENTO}

\section{Características da leptina}

Em 1994, Zhang e col. (9) clonaram e seqüenciaram, em camundongos, o gene que naquele momento foi relacionado à obesidade. Este gene codifica um RNA mensageiro de $4,5 \mathrm{KDa}$ e $84 \%$ de sua seqüência de aminoácidos é idêntica entre humanos e camundongos. A proteína, cujo nome deriva do grego "leptos", que significa magro, é um hormônio composto por 167 aminoácidos, com peso molecular de $16 \mathrm{KDa}$, com $67 \%$ de homologia com outras espécies de primatas (10-12).

A leptina é liberada em pulsos com duração de aproximadamente 30 minutos. Este ritmo diário tem influência hormonal, depende do sexo e da disponibilidade energética, e pode ser alterado pelo horário da alimentação e pela composição da dieta. Em mulheres, durante o dia, no período entre $8 \mathrm{~h}$ e $17 \mathrm{~h}$, foi encontrada por alguns autores a concentração média de 7,63 $\pm 1,20 \mathrm{ng} \cdot \mathrm{mL}^{-1} \mathrm{e}$ durante a noite, das $23 \mathrm{~h}$ às $8 \mathrm{~h}$, de $10,2 \pm 1,70 \mathrm{ng} \cdot \mathrm{mL}^{-1}(13-16)$.

A compreensão do mecanismo de ação da leptina incluiu a identificação de seus receptores, membros da família dos receptores de citocinas, cujo gene é transcrito e clivado em pelo menos 5 diferentes isoformas: o receptor longo $(\mathrm{Ob}-\mathrm{Rb})$, os receptores curtos (Ob-Ra, c e d), além do receptor solúvel (Ob-Re). O receptor longo tem um domínio intracelular de 302 aminoácidos, é expresso em algumas regiões do cérebro e responde às ações centrais da leptina. A isoforma curta do receptor, Ob-Ra, é amplamente distribuída nos diferentes tecidos corporais $(11,14,17)$.

No que diz respeito ao receptor longo, o mecanismo de sinalização intracelular, da mesma forma que para as citocinas, ocorre por mecanismos de fosforilação, ativação da proteína janus-kinase (JAK) e de fatores de transcrição chamados de STATs (signal transducer and activator of transcription), especialmente o STAT-3. Estes se translocam para o núcleo celular, regulando a expressão dos genes-alvo da leptina (18). Além da via JAK-STAT, atualmente sabe-se que a leptina é capaz de ativar a sinalização celular por outros mecanismos, sendo que a ativação da proteína fosfatidilinositol-3kinase merece destaque por ser um ponto de convergência (cross-talk) entre a sinalização da leptina e da insulina. Essa ligação demonstra uma importante relação entre os dois hormônios, com destaque para a regulação hipotalâmica do peso corporal (18).

Os receptores $\mathrm{Ob}-\mathrm{Ra}$, c e d possuem domínio intracelular incapaz de sinalizar pelas vias STATs, e por isso ainda são obscuros os mecanismos de sinalização. 
Alguns estudos in vitro consistiram na adição de leptina a células que expressavam Ob-Ra e, como conseqüência, essas células foram capazes de alterar a expressão de alguns genes. Acredita-se que diferentes proteínas poderiam estar envolvidas nesse mecanismo e, pelo menos em parte, identificou-se alguma ação de MAP-quinases ERK-1 e ERK-2 $(19,20)$.

Estudos recentes indicam que a leptina pode circular na forma livre, ou ainda ligada a receptores solúveis $(\mathrm{Ob}-\mathrm{Re})$, que parecem postergar a ação desse hormônio. Portanto, os receptores solúveis devem aumentar a meia-vida da leptina, e a forma livre seria a mais biologicamente ativa. Foram identificados alguns fatores determinantes da relação entre leptina ligada ao receptor solúvel e leptina livre, dentre eles a idade e hormônios como testosterona, estradiol e insulina (21-23).

\section{Leptina, dieta e balanço energético}

A leptina é considerada um sinal adipostático ao cérebro sobre o balanço energético. Nesse sentido, a leptina age no hipotálamo, principalmente no núcleo arqueado, que é provido de duas populações de neurônios: os orexígenos (subpopulação 1), que basicamente secretam o neuropeptídeo Y e o AgRP (agouti related protein); e os anorexígenos (subpopulação 2), que secretam o CART (transcrito regulado por cocaína e anfetamina) e o $\alpha$-MSH (peptídeo de melanocortina), derivado do POMC (propriomelanocortina). Uma série de sinais em resposta à ingestão ou à privação de alimentos é capaz de se ligar a receptores nessas duas populações de neurônios, de forma a regular a ingestão de alimentos e/ou o gasto energético. A leptina exerce diferentes respostas nessas sub-regiões hipotalâmicas (24). A ligação da leptina ao $\mathrm{Ob}-\mathrm{Rb}$ nos neurônios orexígenos inibe a atividade dessas células e reduz a liberação de NPY e AgRP. Por outro lado, a leptina estimula a atividade dos neurônios anorexígenos, aumentando a liberação de $\alpha$-MSH e CART. Dessa forma, situações que aumentam a concentração plasmática de leptina levam à inibição dos neurônios NPY/AgRP e à estimulação dos neurônios $\alpha$-MSH/CART, causando diminuição da ingestão alimentar. Já situações em que ocorre diminuição na concentração de leptina, os neurônios anorexígenos não estão suficientemente estimulados e os neurônios orexígenos deixam de ser inibidos, levando ao aumento da ingestão alimentar (24). A figura 1 esquematiza esses mecanismos.

A ingestão energética está relacionada com as concentrações de leptina não somente de forma aguda, mas também de forma crônica. A privação de alimentos por 12-48 h diminui a expressão desse hormônio.

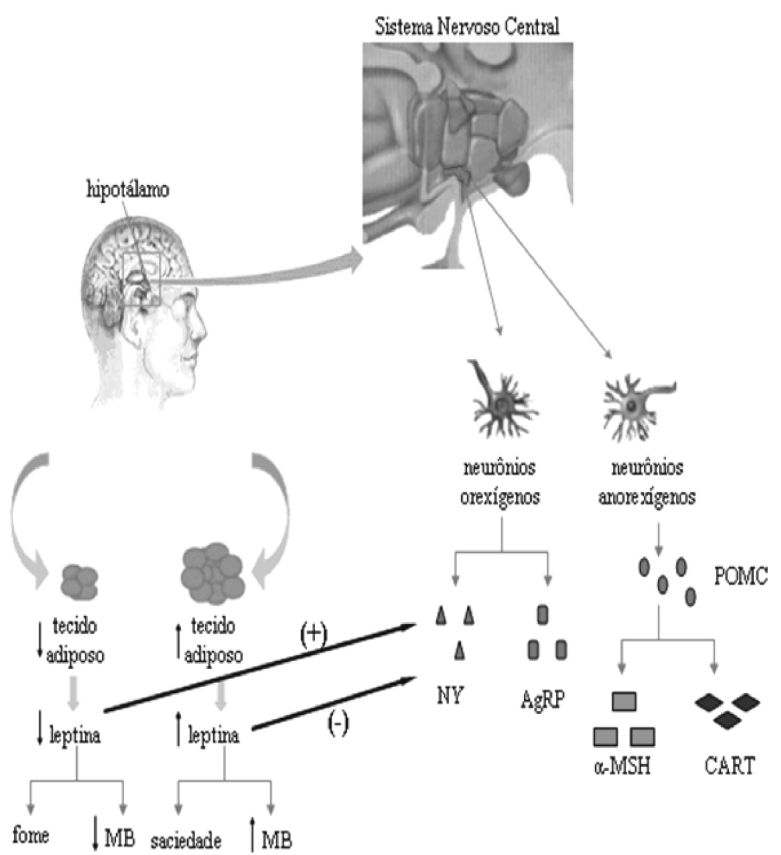

Figura 1. Ação central da leptina no balanço energético. $\mathrm{MB}=$ Metabolismo Basal; $\mathrm{NY}=$ Neuropeptídeo $\mathrm{Y} ; \mathrm{AgRP}=$ proteína relacionada a agouti; $\mathrm{POMC}=$ proteína derivada da propriomelanocortina; $\alpha$-MSH= peptídeos de melanocortina; CART = peptídeo derivado da cocaína.

De forma crônica, $10 \%$ de redução no peso corporal significam cerca de $50 \%$ de queda na leptina circulante, e por outro lado um aumento de $10 \%$ no peso corporal pode elevar a leptina em até $300 \%$. Cabe destacar que as modificações nas concentrações de leptina ocorrem de forma inversamente proporcional à concentração de seu receptor solúvel, o que pode comprovar que esse receptor realmente interfira na biodisponibilidade da leptina $(14,23,25,26)$.

Alguns autores afirmam que a síntese e a liberação de leptina são diferenciadas de acordo com a distribuição do tecido adiposo no corpo, mas não há um consenso nesse sentido. Pisabarro e col. (27), ao avaliarem 39 indivíduos de ambos os sexos com diferentes porcentagens e distribuição de gordura corporal, constataram uma clara relação entre leptina e gordura corporal total, independente de sua tipografia. Por outro lado, Mantzoros (12) afirma que a leptina tem sua expressão mais pronunciada na gordura subcutânea, comparativamente à gordura visceral. Contudo, apenas a distribuição regional da gordura não parece ser uma razão direta para essa diferença. Os hormônios sexuais, que respondem pela diferente distribuição de gordura em homens e mulheres, também guardam relação com a leptina (28).

Vários estudos direcionam para a relação entre hormônios sexuais e leptina, como os descritos a seguir. Foi observado que a concentração de leptina é 
duas a três vezes maior em mulheres que em homens, quando se considera o mesmo Índice de Massa Corporal (IMC) (29). As mulheres necessitam de uma maior liberação de leptina por pulso para manterem o seu peso corporal. Hickey e col. (30), em estudos sobre exercício e leptina, observaram que mulheres, mesmo com menor percentual de gordura corporal que homens, têm maiores concentrações basais de leptina. Isso, na visão de alguns autores, pode significar que as mulheres sejam mais resistentes às ações da leptina que os homens $(15,31)$. Por outro lado, experimentos com animais avaliaram o efeito da injeção de leptina comparando machos e fêmeas, e observaram que as respostas são mais duradouras em fềmeas do que em machos (32).

Indivíduos obesos geralmente têm uma concentração elevada de leptina, e por isso tem sido abordada a hipótese da resistência a esse hormônio. A diminuição da freqüência e amplitude dos pulsos diurnos de leptina em obesos e a diferença nas concentrações de leptina do líquido cefalorraquidiano entre sujeitos obesos e magros colaboram com essa discussão. As prováveis explicações para a resistência giram em torno de alterações nos receptores solúveis, no receptor hipotalâmico ou ainda na resposta do NPY (33). De acordo com Munzberg \& Myers (33), um possível mecanismo para desenvolvimento dessa resistência seria a expressão aumentada do SOCS-3 (supressor de sinalização de citocinas). Este é um mecanismo intracelular que, após a ligação da leptina com seu receptor hipotalâmico, de certa forma regularia a continuidade dessa ligação, similar a um mecanismo de feedback. Whang e cols. (34), estudando ratos velhos, procuraram demonstrar, a partir de técnicas de biologia molecular, uma expressão aumentada desse fator (SOCS3 ). Nesse estudo, os ratos receberam tratamento com leptina visando diminuição das liproteínas de baixa densidade, tratamento que não obteve sucesso. Os autores argumentam que, na ausência ou na sinalização inadequada de leptina (que ocorreria em situações como envelhecimento e obesidade) ocorre um aumento dos ácidos graxos circulantes.

Alguns autores postulam que não ocorra resistência, e sim que seja atingida uma capacidade máxima de saturação ao mecanismo de controle da leptina, e que este hormônio tenha como papel mais importante os mecanismos que sinalizam deficiência energética, e não o controle da obesidade (35).

Ainda como mecanismo central de regulação, sabe-se que a leptina é capaz de influenciar praticamente todos os eixos hormonais, conforme demonstrado na figura 2. Para desempenhar essa ação, a leptina regula a

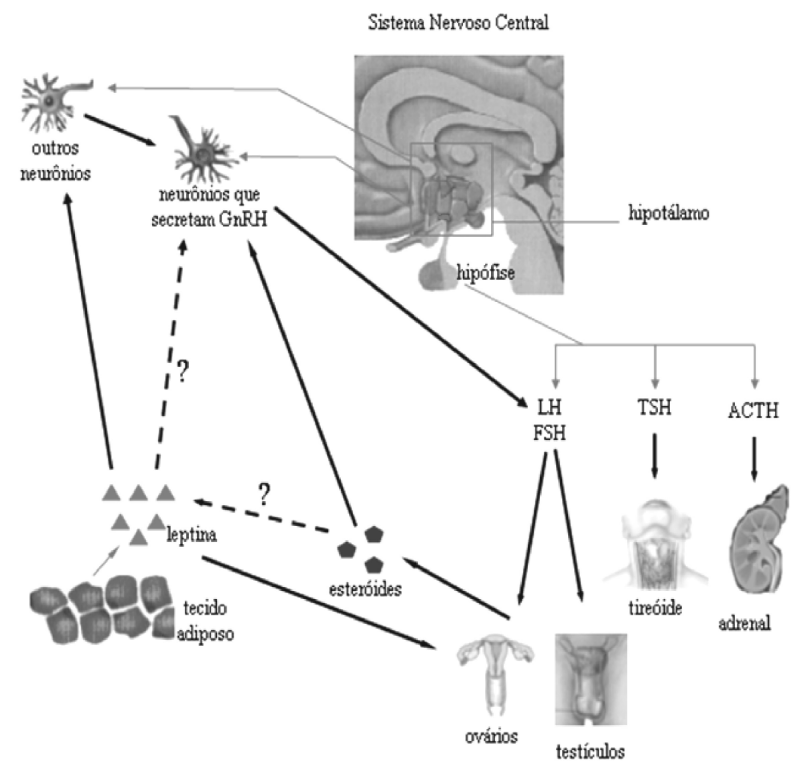

Figura 2. Ação da leptina no eixo reprodutivo e outros eixos hormonais.

$\mathrm{GnRH}=$ fator hipotalâmico de liberação de gonadotrofinas; $\mathrm{LH}=$ hormônio luteinizante; $\mathrm{FSH}=$ hormônio folículo-estimulante; $\mathrm{TSH}=$ hormônio liberador de hormônios da tireóide; $\mathrm{ACTH}=$ fator estimulador do hormônio corticotrófica. [Adaptado de Duclos (4)]

atividade dos diversos neurônios hipotalâmicos que secretam os fatores hipofisiotróficos. Não há evidências conclusivas de que os neurônios que sintetizam esses fatores co-expressem o Ob-Rb, o que indica que seja necessário um controle indireto da leptina na modulação endócrina do organismo. Esse controle possivelmente ocorre pela regulação de sub-populações de neurônios em algumas regiões do hipotálamo que expressam o Ob-Rb, como o núcleo arqueado $(5,8)$.

O estímulo pela leptina de alguns neurônios específicos causa aumento da atividade simpática, resultando em elevação do gasto energético em tecidos periféricos, principalmente no tecido adiposo marrom e no tecido adiposo branco. Em animais, o estímulo simpático relaciona-se com as UCP-1 (uncoupling binding proteins-1) no tecido adiposo marrom. As UCPs funcionam como um canal de $\mathrm{H}^{+}$na membrana mitocondrial interna, pois desacoplam a fosforilação oxidativa resultante do transporte de elétrons, levando à oxidação dos nutrientes sem a ressíntese de ATP, com a maior liberação de energia térmica (calor). Embora a UCP-1 seja a mais conhecida e estudada, sabe-se da existência de outras isoformas em tecidos humanos, como a UCP-2 em diversos tecidos, e a UCP-3 no tecido adiposo branco e no músculo esquelético. Alguns autores tentam demonstrar que a leptina poderia estimular também em humanos a atividade 
dessas UCPs, no músculo esquelético e tecido adiposo branco, colaborando com o aumento do gasto energético. Entretanto, esse assunto ainda é controverso e merece maiores investigações $(36,37)$.

Ainda com relação a mecanismos periféricos de ação da leptina, foi detectada a ativação das vias STATs (e, portanto, a sinalização da leptina) em células intestinais, epiteliais, endoteliais, plaquetas e células $\mathrm{T}$ do sistema imunológico. Existem ainda receptores curtos de leptina nos rins, nos hepatócitos e nas células beta do pâncreas, embora ainda não esteja plenamente compreendido como ocorre a sinalização nesses diferentes tecidos (38-40).

No tecido adiposo branco, no fígado e no músculo esquelético, a leptina provavelmente estimula a oxidação de ácidos graxos, e impede a sua esterificação $(41,42)$. No fígado, a leptina é capaz de inibir o gene da SCD-1 (stearoil-CoA-desaturase). A SCD-1 pode ser considerada uma enzima limitante na biossíntese de ácidos graxos monoinsaturados, a partir de ácidos graxos saturados. A repressão da expressão gênica desta enzima pela leptina favorece a oxidação de ácidos graxos e inibe a síntese de triacilgliceróis no fígado (43). No músculo esquelético, foi demonstrado que o tratamento com leptina estimulou a oxidação de ácidos graxos, especificamente pela ativação da AMPK (proteína quinase ativada pelo AMP). Quando estimulada, a AMPK inibe a ACC (acetil coA carboxilase) a partir da fosforilação de um resíduo de treonina nessa enzima. A inibição dessa enzima diminui, por sua vez, a síntese de malonil- CoA, que seria a primeira etapa da síntese de ácidos graxos. A inibição da síntese de malonil CoA facilita a ação da carnitina acil-transferase I, enzima envolvida no processo de transporte de ácidos para a mitocôndria, com posterior oxidação. Essa capacidade de oxidar ácidos graxos no músculo esquelético é também atribuída ao aumento da expressão do gene FAT/CD36 (que expressa a translocase de ácidos graxos, localizada na membrana celular) (44).

Tem sido bastante estudada a relação entre leptina e metabolismo da glicose, uma vez que é identificada uma relação entre leptina e insulina. A leptina interfere nos mecanismos de sinalização intracelular à insulina, por meio de mecanismos identificados como cross-talk (41), porém não está clara a inter-relação entre esses hormônios. Nas células $\beta$ do pâncreas, alguns autores constataram que a leptina é capaz de inibir a expressão de insulina (18). Por sua vez, em resposta à alimentação, as concentrações de leptina aumentam com a elevação da insulina, e, no jejum, diminuem após a redução da insulina (46). Existem ainda observações de hipoleptinemia associada à hipo- insulinemia em mulheres atletas, sugerindo que alterações crônicas da insulina modulam a síntese de leptina $(12,42,46)$.

Koutsari e col. (47) observaram as concentrações de leptina em indivíduos submetidos a exercício físico e dieta com alto percentual de carboidratos (70\% do valor energético total ingerido), comparativamente a um grupo controle, com baixa ingestão de carboidratos. Foi observada uma maior concentração de leptina de jejum e pós-prandial nos grupos com elevado consumo de carboidratos.

A ingestão de micronutrientes também pode regular as concentrações de leptina. Existem evidências de que o zinco pode influenciar este hormônio, até porque esse mineral é co-fator para a expressão do gene ob. As concentrações de leptina diminuem em resposta a restrição de zinco e aumentam posteriormente a um período de suplementação (12).

\section{Leptina e exercício físico}

O exercício físico causa uma série de modificações metabólicas no organismo. De forma aguda, pode-se destacar o aumento do gasto energético necessário para sua realização e a mobilização de substratos energéticos específicos. De forma crônica, considerando a adaptação do organismo ao treinamento, destaca-se a modificação na composição corporal e a capacidade aumentada de armazenar carboidratos e triacilgliceróis no músculo esquelético. Todas essas modificações estão relacionadas a fatores como idade, sexo, grau de treinamento, além do tipo e da intensidade do exercício (48).

A partir do conhecimento das ações da leptina e tendo em mente as respostas ao exercício, algumas questões poderiam ser formuladas: a leptina é necessária para que as ações metabólicas dos diferentes tipos de exercício possam ocorrer?; o gasto energético aumentado em decorrência do exercício teria como mediador leptina?; o treinamento físico extremo, que resulta em alterações na composição corporal e conseqüente diminuição nas concentrações de leptina, pode provocar efeitos deletérios aos demais eixos hormonais?; o exercício poderia aumentar a sensibilidade hipotalâmica à leptina, fazendo com que o organismo ajuste seu balanço energético mais eficientemente? A maioria das publicações sobre o tema até recentemente tem centrado a investigação nas modificações na concentração da leptina em diferentes protocolos de exercício, desde respostas imediatas até após meses de treinamento. As relações dessas respostas com o eixo reprodutor também têm sido investigadas.

Tem sido comum o relato de que o exercício físico, de forma aguda ou crônica, causa diminuição nas concentrações de leptina. Uma questão oriunda dessa 
informação é se o exercício, por si só, causa essa redução, ou se a diminuição na gordura corporal, resposta típica ao treinamento físico, ou ainda o desbalanço energético criado, não seriam responsáveis por essa diminuição (14). Além disso, não está claro se o exercício poderia aumentar a sensibilidade da leptina em seus receptores centrais e/ou periféricos. Deve haver uma concentração ótima de leptina que torna o exercício benéfico, e abaixo desta concentração, principalmente em mulheres, a sinalização hormonal pode ser alterada. As tabelas 1, 2 e 3 apresentam a descrição e o resultado de alguns estudos realizados nesse contexto.

A oxidação de substratos energéticos para $o$ exercício, como a glicose e os ácidos graxos, altera as concentrações de leptina. Por isso, a redução da con- centração desse hormônio em decorrência do exercício pode ser devida a alterações da disponibilidade ou do fluxo de nutrientes nos adipócitos $(14,46)$.

Modificações na composição corporal também estão relacionadas com as alterações na leptina. Alguns estudos demonstraram que a diminuição do tecido adiposo em resposta ao exercício está relacionada a alterações no receptor longo, $\mathrm{Ob}-\mathrm{Rb}$. Kimura (49) investigou, em ratos, se o exercício espontâneo regulou a expressão da leptina após um período de 12 semanas. Os ratos apresentaram redução na gordura corporal e diminuição na concentração de leptina, além de downregulation no mRNA do receptor. Os autores especularam o possível papel da insulina nessas respostas.

Tabela 1. Estudos avaliando alterações agudas nas concentrações de leptina com exercícios aeróbios.

\begin{tabular}{|c|c|c|}
\hline Autor e ano & $\begin{array}{c}\text { Protocolo experimental e controle da dieta ou } \\
\text { gordura corporal }\end{array}$ & $\begin{array}{c}\text { Alterações na concentração de } \\
\text { leptina }\end{array}$ \\
\hline Essig e cols., 2000 (92) & $\begin{array}{l}\text { Exercício em homens, a } 70 \% \text { do } \mathrm{VO}_{2} \text { máx que resulta } \\
\text { em gasto energético de } 1500 \mathrm{KCal} \text { comparado aos } \\
\text { mesmos indivíduos submetidos a gasto energético } \\
\text { de } 800 \mathrm{KCal} \text {. }\end{array}$ & $\begin{array}{l}\text { Diminuição de } 30 \% \text { com o exercício de } \\
1500 \text { Kcal; sem alteração com } 800 \text { KCal. }\end{array}$ \\
\hline Tuominen e cols., 1997 (93) & $\begin{array}{l}\text { Comparação em homens saudáveis de: a) hiperglice- } \\
\text { mia induzida, b) exercício com depleção do } \\
\text { glicogênio. }\end{array}$ & $\begin{array}{l}\text { Diminuição de } 34 \% \text { no grupo exercita- } \\
\text { do, sugerindo que a homeostase de } \\
\text { nutrientes é fator determinante da alte- } \\
\text { ração aguda de leptina. }\end{array}$ \\
\hline Hilton \& Loucks, 2000 (94) & $\begin{array}{l}\text { Comparação de três protocolos: a) exercício; b) res- } \\
\text { trição energética; c) exercício + restrição energética. }\end{array}$ & $\begin{array}{l}\text { Diminuição } 24 \text { h após o exercício } \\
\text { somente na combinação de exercício e } \\
\text { restrição energética, sugerindo que a } \\
\text { disponibilidade de nutrientes é fator } \\
\text { determinante. }\end{array}$ \\
\hline Kraemer e cols., 1999 (95) & $\begin{array}{l}30 \text { min em esteira ergométrica a } 80 \% \text { do } \mathrm{VO}_{2} \text { máx, } \\
\text { mulheres menopausadas, } 2 \text { grupos: com reposição } \\
\text { hormonal e sem reposição hormonal; não houve } \\
\text { controle da dieta; foi medida a leptina durante o } \\
\text { exercício e após } 2 \text { h do término do exercício. }\end{array}$ & $\begin{array}{l}\text { Sem diferenças quando comparado a } \\
\text { uma sessão controle, sem exercício. }\end{array}$ \\
\hline Duclos e cols., 1999 (96) & $\begin{array}{l}\text { Resposta, em homens maratonistas (baixa gordura } \\
\text { corporal), a uma sessão de } 2 \mathrm{~h} \text { de exercício, compa- } \\
\text { rada a um período de descanso. }\end{array}$ & $\begin{array}{l}\text { Diminuição de } 30 \% \text {, que foi atribuída a } \\
\text { lipólise aumentada em indivíduos } \\
\text { treinados. }\end{array}$ \\
\hline Torjman e cols., 1999 (97) & $\begin{array}{l}\text { Em homens não treinados, esteira ergométrica du- } \\
\text { rante } 60 \text { min, em três diferentes momentos: a } 50 \% \\
\text { do } \mathrm{VO}_{2} \text { máx, esforço máximo e sessão controle. } \\
\text { Coleta de sangue } 60,120,180 \text { e } 240 \text { min. }\end{array}$ & $\begin{array}{l}\text { Sem alteração, quando comparados à } \\
\text { sessão controle. }\end{array}$ \\
\hline Leal-Cerro e cols., 1998 (98) & $\begin{array}{l}\text { Atletas homens que completaram uma maratona ( } 42 \\
\mathrm{~km} \text { ) com gasto energético de } 2800 \mathrm{Kcal} \text {, comparados } \\
\text { com controles sedentários. }\end{array}$ & $\begin{array}{l}\text { Atletas têm menor gordura corporal e } \\
\text { menor leptina; após a maratona houve } \\
\text { diminuição na leptina. }\end{array}$ \\
\hline Fisher e cols., 2001 (99) & $\begin{array}{l}\text { Homens com baixa gordura corporal, } 41 \text { min de ci- } \\
\text { clismo a } 50 \% \text { do } \mathrm{VO}_{2} \text { máx, comparativamente a uma } \\
\text { situação controle. }\end{array}$ & $\begin{array}{l}\text { Elevação na leptina durante ao exercício } \\
\text { (que os autores atribuíram ao cortisol) e } \\
\text { diminuição de } 10 \% \text { após o exercício. }\end{array}$ \\
\hline Landt e cols., 2000 (100) & $\begin{array}{l}\text { Corredores que completaram uma ultra maratona } \\
(162,5 \mathrm{~km}) \text {; sem controle da dieta. }\end{array}$ & Redução de $32 \%$. \\
\hline
\end{tabular}


Tabela 2. Estudos avaliando alterações crônicas nas concentrações de leptina com exercícios aeróbios.

Autor e ano

Protocolo experimental e controle da dieta

\section{Alterações na concentração de leptina}

Franks e cols., 2003 (101)

Protocolo experimental e controle da dieta. Avaliação populacional do nível de atividade física (PAEE) em 758 adultos entre 40-65 anos.

Reseland e cols., 2001 (102) 186 homens com síndrome metabólica, 4 grupos: a) dieta; b) exercício; c) dieta + exercício; d) controles. Intervenção de um ano.

Perusse e cols., 1997 (103) 20 semanas de treinamento aeróbio em homens e mulheres sedentários; sem controle da dieta.
A leptina demonstrou correlação inversa com o nível de atividade física.

A dieta e o exercício foram capazes, isoladamente ou combinados, de reduzir as concentrações de leptina.

Redução após o período de treinamento somente nos homens; sem diferenças quando os dados foram normalizados pelo IMC.
Kraemer e cols., 1999 (95)

Gutin e cols., 1999 (104)

Okazaki e cols., 1999 (105)

Pasman e cols., 1998 (26)
9 semanas de treinamento aeróbio em mulheres obe- Sem alteração. sas de meia-idade; sem modificação de peso, mas com aumento do $\mathrm{VO}_{2}$ máx.

4 meses de exercícios em crianças obesas contra um grupo controle; sem controle da dieta.

Mulheres de meia-idade, grupo obesas e não obesas, sedentárias. Treinamento aeróbio $\left(50 \%\right.$ do $\mathrm{VO}_{2}$ máximo) + aconselhamento dietético individual, durante 12 semanas.

Treinamento aeróbio em 15 homens obesos. Nos 4 primeiros meses todos foram submetidos a restrição energética severa + treinamento diário de intensidade moderada. Nos 4 meses subseqüentes, foram formados dois grupos: um deles interrompeu o treinamento e continuou com a dieta. O outro grupo manteve o esquema inicial.
Diminuição no grupo exercitado e aumento no grupo controle.

Diminuição da leptina em todos, inclusive nas que não tiveram redução no tecido adiposo.

Ambos os grupos, a despeito das diferenças na concentração de insulina e da gordura corporal, tiveram as concentrações de leptina reduzidas.

Tabela 3. Estudos avaliando alterações nas concentrações de leptina com exercícios resistidos.

\begin{tabular}{lll}
\hline \multicolumn{1}{c}{ Autor e ano } & \multicolumn{1}{c}{ Protocolo experimental e controle da dieta } & $\begin{array}{c}\text { Alterações nas concentrações de } \\
\text { leptina }\end{array}$ \\
Ryan e cols., 2000 (106) & $\begin{array}{l}16 \text { semanas de exercício resistido em mulheres } \\
\text { menopausadas. Comparação entre grupos: a) exercí- } \\
\text { cio resistido; b) exercício resistido + dieta. }\end{array}$ & $\begin{array}{l}\text { Diminuição apenas no grupo que com- } \\
\text { binou dieta. Leptina correlacionou-se } \\
\text { com peso corporal, gasto energético de } \\
\text { repouso e insulina. }\end{array}$ \\
Zafeiridis e cols., 2003 (107) & $\begin{array}{l}\text { Três diferentes protocolos de exercício resistido: a) } \\
\text { hipertrofia muscular; b) resistência muscular; c) força } \\
\text { máxima. Sem controle da dieta. }\end{array}$ & $\begin{array}{l}\text { Sem diferenças nos três grupos. } \\
\text { Os indivíduos obesos apresentaram } \\
\text { maiores concentrações de leptina. }\end{array}$ \\
\hline Gippini e cols., 1999 (108) & $\begin{array}{l}\text { Três grupos de homens, idade média 27 anos: a) } \\
\text { sedentários com sobrepeso; b) sedentários eutróficos } \\
\text { (grupo controle); c) praticantes de musculação. Sem } \\
\text { controle da dieta. }\end{array}$ & $\begin{array}{l}\text { Quando a leptina foi corrigida pelo total } \\
\text { de gordura corporal, não houve diferen- } \\
\text { ças grupos. }\end{array}$ \\
\hline
\end{tabular}


Cabe ainda investigar o possível papel da leptina no anabolismo protéico, em exercícios para hipertrofia muscular. Existe um importante papel do eixo somatotrófico (GH-IGF-I) nos processos anabólicos musculares, e parece que a leptina é capaz de influenciar, direta ou indiretamente, esse eixo. $\mathrm{O}$ fato de o GH (hormônio de crescimento) ter funções diretas e indiretas torna difícil investigar a relação da leptina com esse eixo (50). Na obesidade observa-se alta concentração de leptina e baixa concentração de GH; já na restrição alimentar, observa-se aumento do $\mathrm{GH}$ e diminuição na concentração de leptina. No caso dos exercícios resistidos, é possível que a leptina aja diretamente estimulando a síntese de IGF-I no músculo esquelético, independentemente do GH $(51,52)$. Também cabe destacar que, como a leptina exerce influência nas concentrações dos hormônios sexuais, estes, por sua vez, podem ter um papel relevante na regulação do metabolismo protéico no organismo, e conseqüentemente nos processos de hipertrofia muscular.

\section{Relação entre leptina, exercício, balanço energético e sistema reprodutor}

O ciclo menstrual da mulher pode ser dividido em três fases: fase folicular (essencialmente estrogênica), ovulação e fase lútea (essencialmente progestagênica). Para que ocorram todas as fases se faz necessária uma integração perfeita dos hormônios e de fatores liberadores hipotalâmicos, hipofisários e ovarianos, em freqüência e amplitude. O hipotálamo secreta o GnRH em pulsos que duram alguns minutos e que ocorrem em intervalos de uma a três horas. A liberação de GnRH leva à produção hipofisária, também pulsátil, do hormônio luteinizante (LH), e em menor escala, do hormônio folículo estimulante (FSH). Esses hormônios, por sua vez, estimulam os ovários a produzir estrógeno e progesterona (53).

A função principal dos estrógenos no ciclo menstrual é estimular o crescimento do endométrio uterino, provocando um aumento tanto no número de células (hiperplasia) como no tamanho das mesmas (hipertrofia). Os estrógenos, além de exercem ações sobre a maioria dos órgãos ou tecidos diretamente relacionados às funções reprodutoras, têm ação sobre o metabolismo e deposição de gorduras e de proteínas, sobre o tecido ósseo, sobre o sistema nervoso central, sobre o sistema cardiovascular e sobre o sistema hematopoiético (53-55).

Alterações na secreção pulsátil do GnRH podem modificar a liberação de LH, FSH e de esteróides ovarianos. Esta situação pode ocorrer quando as mulheres se encontram em estado de amenorréia (56).
Pode-se classificar a amenorréia hipotalâmica em dois tipos: amenorréia primária, quando em uma menina de 16 anos há ausência de menstruação e não há presença dos caracteres sexuais secundários (mamas, pêlos pubianos, estirão do crescimento); amenorréia secundária, quando ocorre ausência de menstruação por um período maior do que três meses em uma mulher que anteriormente já apresentou ciclos menstruais (57).

A amenorréia hipotalâmica funcional é definida como a cessação da menstruação por disfunções de sinais do hipotálamo à hipófise, resultando em alterações na ovulação. Nesse caso, a amenorréia é causada pela secreção insuficiente e/ou anormal de GnRH, o que implica em supressão na liberação de gonadotrofinas e, por conseguinte, do eixo hormonal reprodutivo. Ainda não foi possível evidenciar quais variáveis estão relacionadas com a diminuição da atividade dos neurônios GnRH que levam à amenorréia hipotalâmica funcional. Sabe-se que essas mulheres, de uma forma geral, têm baixo peso, podem ser atletas, estar envolvidas com atividades intelectuais, ou ainda serem expostas a fatores estressantes. Independentemente da situação ambiental que levou à amenorréia, é freqüentemente observado um desbalanço nutricional, geralmente no que diz respeito a energia, mas também a nutrientes específicos $(58,59)$.

A leptina tem um papel integrador entre o estado nutricional e os eixos hormonais, sendo um indicador dos estoques de energia para um funcionamento normal do sistema reprodutivo $(15,60,61)$. Assim, a manutenção de uma concentração mínima de leptina é necessária para uma secreção adequada dos hormônios luteinizante ( $\mathrm{LH})$ e folículo-estimulante (FSH) $(12,46)$. Alguns autores sugerem que concentrações de leptina abaixo de $3 \mathrm{ng} . \mathrm{mL}^{-1}$, ou gordura corporal abaixo de $15 \%$ tornam aumentados os riscos de cessação da menstruação (62-64), porém sabe-se que existe uma variabilidade individual bastante grande, tornando questionável o estabelecimento de pontos de corte.

Welt e col. (58) tentaram comprovar o papel da leptina na sinalização do eixo reprodutor. Em mulheres diagnosticadas como amenorréia hipotalâmica funcional, foi administrada leptina durante um período de três meses. Das oito mulheres às quais foi administrada leptina, três reiniciaram a ovulação e outras três tiveram expressiva mudança nos folículos caracterizando uma situação pré-ovulatória. Zerani e col. (65), em estudos com coelhos e usando técnicas de imuno-histoquímica e Western blotting em tecido ovariano, observaram uma função luteolítica permissiva da leptina. Na mesma linha de raciocínio, Chan e 
col. (66) submeteram homens a $72 \mathrm{~h}$ de jejum e em seguida dividiram esses indivíduos em dois grupos: os que simplesmente permaneceram em jejum e os que, além do jejum, receberam uma dose de leptina recombinante. A reposição de leptina foi capaz de impedir a supressão nas concentrações plasmáticas de testosterona, $\mathrm{LH}$ e FSH, observada em decorrência do jejum.

A leptina pode ainda ser um sinal que alerta ao cérebro que as reservas de gordura já possibilitam o início da puberdade, da manutenção do ciclo menstrual e da habilidade de reprodução. Em meninas, a leptina se relaciona inversamente com a idade da menarca. A partir de aproximadamente 10 anos de idade, as concentrações de leptina diminuem nos meninos à medida que se elevam as concentrações de testosterona, e se eleva nas meninas proporcionalmente ao aumento do estradiol. Alguns estudos longitudinais investigaram leptina, idade da menarca e composição corporal. Um estudo realizado com 789 crianças e adolescentes, de ambos os sexos, entre cinco e 15 anos, demonstrou que as concentrações de leptina aumentam tanto em meninos quanto nas meninas antes que aumentem outros hormônios relacionados ao início da puberdade $(3,28,67-70)$. A ação permissiva da leptina no desencadeamento do início da puberdade foi testada em camundongos fềmeas pré-púberes que receberam injeções de leptina. Foi observado que, apesar de os animais tratados com leptina apresentarem um menor peso corporal, eles entraram na puberdade nove dias antes que os animais controle e apresentaram uma maturação do trato reprodutivo mais rapidamente (71).

No que diz respeito a leptina e maturação sexual, também é importante destacar a presença do seu receptor solúvel. Em meninas, na medida em que a idade evolui, aumenta a concentração de leptina livre e diminui a concentração de seus receptores solúveis. Em meninos, essa proporção é inversa. Ainda, a diminuição nos receptores solúveis em mulheres e o aumento desses em homens são proporcionais às concentrações de estradiol e testosterona, respectivamente $(22,23)$.

Como já citado anteriormente, ainda não está claro como a leptina regula a secreção de GnRH. A maior parte das evidências disponíveis aponta para uma regulação indireta da leptina sobre os neurônios $\mathrm{GnRH}$, pois apenas estudos utilizando técnicas in vitro com células imortalizadas de GnRH foram capazes de detectar a presença do receptor de leptina (72). Diante deste fato, outras regiões que expressam o receptor de leptina, como é o caso de neurônios nos núcleos arqueado, dorso medial do hipotálamo e pré-mamilar ventral, provavelmente recebem a informação da leptina e, por meio de projeções para os próprios neurônios $\mathrm{GnRH}$ na área pré-óptica ou para áreas reconhecidamente capazes de influenciar a atividade desses neurônios, como o hipotálamo periventricular anteroventral (HPAV), regulam a secreção deste fator hipofisiotrófico $(50,73)$. Cabe ressaltar que esse tipo de regulação indireta é característico dos neurônios $\mathrm{GnRH}$, pois mesmo a ação de feedback dos esteróides sexuais é realizada por regiões que se projetam para os neurônios GnRH (74).

Evidências têm indicado que a leptina utiliza diversos neuromoduladores para controlar a secreção de GnRH. Entre os candidatos mais prováveis estão o CART e o óxido nítrico (NO). Ambos são produzidos em regiões influenciadas pela leptina, por neurônios que co-expressam o OB-Rb e que se projetam diretamente para os neurônios GnRH ou para áreas hipotalâmicas importantes na regulação do sistema reprodutivo $(5,73)$. Uma informação adicional que merece destaque foi a recente descoberta de uma proteína chamada kisspeptin (kiss-1) ou metastin, inicialmente estudada por sua capacidade de inibir a migração de alguns tipos de células de câncer, e de seu receptor GPR54 (receptor 54 acoplado à proteína G). Observou-se que esta proteína estaria envolvida com a regulação da capacidade reprodutiva (75). Diversos estudos observaram que a proteína kiss- 1 seria um potente estimulador da produção de GnRH e, por conseqüêencia, de gonadotrofinas, sendo que neurônios GnRH expressam o GPR54 (76). Mutações no GPR54 causam hipogonadismo em animais e seres humanos. Além disso, existem evidências do envolvimento da kiss-1 com o desencadeamento da maturação sexual e no controle de feedback dos hormônios gonadais na expressão de GnRH (75). Ainda, a expressão de kiss-1 é abundante em regiões influenciadas direta ou indiretamente pela leptina, como é o caso do núcleo arqueado e do paraventricular $(75,77)$. Como perspectiva, é possível que esses mecanismos relacionados à kisspeptin e conseqüentemente ao GnRH também sejam regulados pela concentração de leptina, porém mais estudos ainda são necessários (67-69).

Diferentes autores demonstraram a ação da leptina em vários locais do sistema reprodutor. Em ratos, são encontradas isoformas dos receptores curtos de leptina nos ovários, especificamente nas células ovarianas foliculares e nas células de Leydig, nos testículos e no útero. O RNAm de leptina também é expresso nos folículos pré-ovulatórios, sugerindo que a leptina tenha funções autócrinas e parácrinas nas gônadas. Em humanos, são evidentes os receptores de leptina nos 
ovários e nos testículos (78). A ação da leptina sobre os ovários é pouco compreendida, mas sabe-se que deve existir uma concentração ótima desse hormônio para o funcionamento normal dos órgãos. Abaixo dessas possíveis concentrações, a multiplicação celular e o amadurecimento dos oócitos não ocorreriam, e por outro lado a concentração muito elevada de leptina seria responsável por alterações nesse órgão, como por exemplo a síndrome dos ovários policísticos, que converge com obesidade e anovulação crônica $(12,16$, 61,67-69,78,79).

Alguns autores afirmam que o estradiol e o FSH podem influenciar a produção da leptina pelos adipócitos. Outros demonstraram que as concentrações de leptina alcançam seu pico máximo na fase lútea, coincidindo com as concentrações máximas de progesterona (68).

Apesar de ser tão discutido o papel central da leptina na modulação do eixo reprodutor, estudos procuram demonstrar que esse mecanismo seria indireto, ou seja, se a leptina interfere no metabolismo energético de células periféricas, estes processos seriam responsáveis pelo funcionamento normal do sistema reprodutor. Schneider e Zhou (80) estudaram o comportamento sexual e a ciclicidade do ciclo estral em hamsters, simulando um bloqueio da oxidação periférica de lipídeos (administrando metil palmoxirato ou MP, que bloqueia a ação da carnitina palmitoilcaboxilase) ou carboidratos (administrando 2DG-desoxi-glicose, que compete com a glicose nas vias de oxidação). Os autores observaram que o ciclo estral não foi normalizado quando a administração de leptina era feita concomitantemente com um ou com os dois inibidores.

Em muitas mulheres envolvidas com treinamento físico intenso, tem sido bastante estudada a chamada "tríade da mulher atleta". Esta consiste em transtornos alimentares, amenorréia e osteoporose (81). A amenorréia pelo exercício tem incidência que pode atingir $44 \% \mathrm{em}$ atletas competitivas, comparado com a incidência de 1 a $5 \%$ entre a população geral (16). Estima-se que a ocorrência de amenorréia exista em 30 a $50 \%$ das bailarinas profissionais, $50 \%$ das corredoras competitivas, $25 \%$ das corredoras não competitivas e $12 \%$ das nadadoras e ciclistas. Ginastas, tendo seu estado nutricional avaliado, demonstraram baixo percentual de gordura e retardo no aparecimento dos caracteres sexuais $(82,83)$. É importante ainda destacar estudos prospectivos que demonstraram a existência de alterações ovulatórias subclínicas em mulheres que praticam exercícios de forma recreativa. Essas alterações incluem uma maior fase folicular compensadas por uma curta fase luteal, fatores esses que não são detectados pelos critérios diagnósticos de amenorréia (64).

Vários estudos associam o baixo peso e as reservas diminuídas de gordura corporal das atletas como causa do desenvolvimento de amenorréia. A ingestão alimentar deficiente resulta em um balanço energético negativo, e a combinação de alto gasto energético provocado pelo treinamento pode ser a causa distúrbios menstruais $(1,2,83-85)$.

O elo entre a dependência da pulsatilidade de LH sobre a disponibilidade de energia é mediado pela leptina. Tem sido demonstrado que tanto a freqüência de pulso como a amplitude e a área sobre a curva de LH são menores em corredoras, quando comparadas a um grupo controle não atleta. Autores demonstraram também que a concentração plasmática de leptina durante as 24 horas do dia é três vezes menor nas atletas, independentemente de seu período do ciclo menstrual, comparado a mulheres sedentárias $(1,3,52,63$, $68,86,87)$.

De uma forma resumida, poderia ser traçado um esquema resumido da origem da amenorréia:
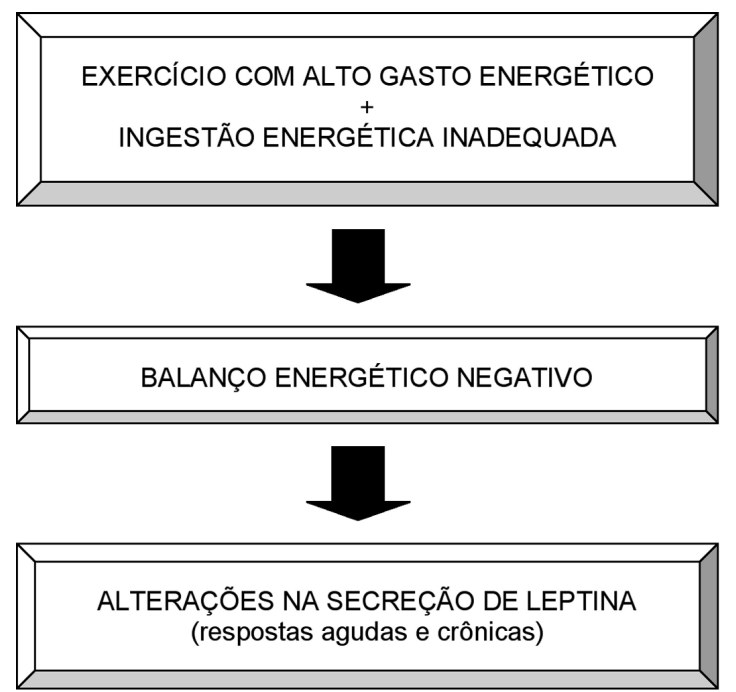

(Ações diretas e/ou indiretas)

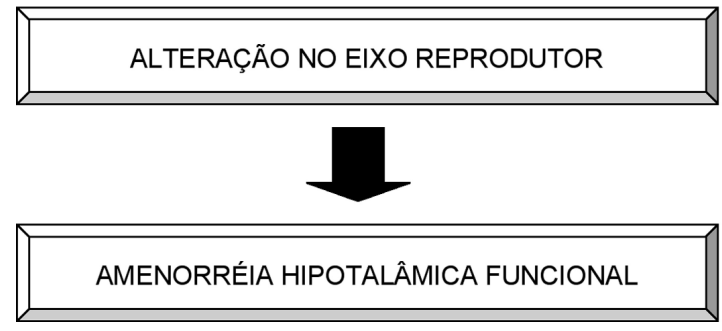

Arq Bras Endocrinol Metab 2007;51/1 
A amenorréia em atletas é acompanhada por estados de hipoglicemia, hipoinsulinemia, hipercortisolemia, redução da taxa de metabolismo basal, hipoleptinemia com redução dos picos diurnos desse hormônio. Nessas atletas não existe o padrão circadiano de secreção de leptina, presente nas atletas com ciclos regulares e mulheres sedentárias (68). Na perspectiva de compreender com profundidade o surgimento da amenorréia em atletas, seria importante a comparação desse processo com outro fenômeno bastante comum em atletas envolvidos em treinamentos extenuantes, a chamada síndrome do overtraining. De forma geral essa síndrome consiste em treinamento excessivo, período de recuperação insuficiente para a supercompensação das reservas metabólicas, e ainda uma ingestão alimentar inadequada. São várias as tentativas de explicar essa síndrome, e dentre as várias conseqüências de seu surgimento são descritas a diminuição do apetite e a supressão do eixo reprodutor $(87,88)$. Considerando a relação entre a síndrome do overtraining com processos inflamatórios locais e sistêmicos, poder-se-ia supor que o aumento da produção de citocinas próinflamatórias resultante do treinamento intenso e da alimentação inadequada poderia levar a alterações na sinalização hipotalâmica da leptina, modificando os sinais referentes à ativação simpática, fome, apetite, funcionamento de eixos hormonais, e conseqüentemente à amenorréia do esforço (89).

\section{Estratégias e recomendações para a mulher atleta}

A partir dos aspectos abordados no presente manuscrito, fica claro que a amenorréia do esforço deve ser evitada, pois, mesmo que seus riscos à saúde não estejam totalmente esclarecidos, ela pode ser um dos aspectos relacionados à tríade da mulher atleta. $\mathrm{O} \mathrm{Co}^{-}$ légio Americano de Medicina do Esporte (ACSM) tem elaborado periodicamente várias recomendações para os aspectos considerados polêmicos no mundo do esporte e, no que diz respeito a essa tríade, é sugerido um amplo esclarecimento a todos os que fazem parte do dia a dia da atleta, incluindo treinadores e familiares. Como estratégias, alguns pontos devem ser considerados:

- Um fator primordial é a adequação das necessidades energéticas ao consumo alimentar. A escolha de métodos apropriados para avaliação do gasto energético, tal como a calorimetria indireta, são ferramentas a serem pensadas. $\mathrm{O}$ estabelecimento da necessidade energética dos indivíduos deve levar em consideração, além do nível de atividade física, a idade, o sexo, características genéticas, entre outros. De uma forma geral, o ACSM destaca que pessoas fisicamente ativas devem ter uma ingestão energética entre 1,5 a 1,7 vezes o seu gasto energético de repouso. Pode-se ainda sugerir, para atletas de endurance (exercícios de longa duração), uma ingestão de $37-4 \mathrm{l} \mathrm{Kcal} / \mathrm{Kg}$ de peso corporal/dia e para atletas de resistência muscular (exercícios de alta intensidade) entre 44-50 $\mathrm{Kcal} / \mathrm{Kg}$ de peso corporal/dia, quando em fase de hipertrofia muscular. Entretanto, considerando os aspectos individuais, deve-se considerar como ingestão energética adequada aquela capaz de manter um balanço energético positivo, o que pode ser avaliado pela manutenção do peso corporal $(57,90)$.

- A escolha e a interpretação de métodos de avaliação da composição corporal, de forma periódica, são fundamentais. Desta forma, a perda de peso deve ser criteriosamente acompanhada, de forma a evitar perda de massa magra ou ainda um percentual crítico de gordura corporal. Da mesma forma, a avaliação periódica do consumo alimentar e do nível de atividade física fazem parte da monitorização adequada da atleta.

- Os processos rápidos de perda de peso não devem ser estimulados e um acompanhamento nutricional adequado é fundamental. Quando a perda de peso for realmente necessária, devem-se estabelecer metas compatíveis com a manutenção da saúde. A perda de peso deve ser preconizada sempre em períodos fora de temporadas competitivas, e deve ser estabelecida a partir de ingestões energéticas que estejam no máximo entre 10-20\% abaixo da ingestão habitual.

-A ingestão de carboidratos deverá abranger o intervalo entre 6-10 g/ $\mathrm{Kg}$ de peso corporal/dia, ajustando-se aos períodos de maior ou menor treinamento.

-Adequação da ingestão de proteínas, atingindo $1,2-1,4 \mathrm{~g} / \mathrm{Kg}$ de peso corporal/dia para atletas de endurance e 1,6-1,8 $\mathrm{g} / \mathrm{Kg}$ de peso corporal/dia para atletas de resistência muscular.

-As gorduras, além de serem necessárias para fins energéticos e para síntese hormonal, são importantes veículos de vitaminas lipossolúveis e de ácidos graxos essenciais. Não há benefícios comprovados com dietas que tenham um percentual menor que $15 \%$ de gordura. Como meta ideal, os lipídeos devem contemplar de $20-25 \%(57,90,91)$.

\section{CONSIDERAÇÕES FINAIS}

O exercício físico traz benefícios fisiológicos, metabólicos e psicológicos. Entretanto, a busca de todos esses benefícios pode gerar efeitos contrários, sem um planejamento alimentar e treinamento adequado. As 
alterações no eixo reprodutor, que podem culminar em amenorréia hipotalâmica funcional, são algumas das respostas indesejáveis à combinação inadequada de dieta e exercícios físicos. A amenorréia hipotalâmica induzida pelo exercício é um processo bastante comum, sendo a leptina um hormônio-chave nesse processo.

$\mathrm{Na}$ amenorréia, cessam ou diminuem significativamente os sinais hipotalâmicos do GnRH, tendo como conseqüências a diminuição do LH, FSH e hormônios ovarianos, principalmente os estrógenos. Estes últimos são fundamentais para a manutenção da massa óssea, da concentração plasmática adequada de lipoproteínas, além, obviamente, da fertilidade.

Sob o ponto de vista nutricional, o estabelecimento correto do gasto energético induzido pelo esforço é fator primordial nessa discussão. A busca de métodos adequados de avaliação é de extrema importância. É necessário que se compreenda que o exercício aumenta o gasto energético não somente durante a sua execução, mas também no período de recuperação. Além disso, o treinamento físico induz adaptações no organismo que permitem a mobilização maior de nutrientes específicos como ácidos graxos e glicose.

Concluindo, com a presente revisão foi demonstrada a importância da identificação dos processos metabólicos envolvidos com a amenorréia, o papel da leptina e a importância da nutrição adequada nessa discussão. O esforço conjunto dos profissionais envolvidos na elaboração do treinamento físico e da alimentação é fundamental nessa perspectiva.

\section{AGRADECIMENTOS}

O autor José Donato Junior agradece à FAPESP pela bolsa de estudo concedida (processo número 05/58997-4).

\section{REFERÊNCIAS}

1. Pardini DP. Alterações hormonais da mulher atleta. Arq Bras Endocrinol Metab 2001;45(4):343-51.

2. Williams NI, Helmreich DL, Parfitt BD, Caston-Balderrama A, Cameron JL. Evidence for a causal role of low energy availability in the induction of menstrual cycle disturbances during strenuous exercise training. J Clin Endocrinol Metab 2001;86(11):5184-93.

3. Yu WH, Kimura M, Walczewska A, Karanth S, McCann SM. Role of leptin in hypothalamic-pituitary function. Proc Natl Acad Sci 1997;94(102):1023-8.

4. Duclos M. Effects of physical training on endocrine functions. Ann Endocrinol 2001;1(1 pt. 1):19-32.

5. Chan JL, Mantzoros CS. Leptin and the hypothalamic-pituitary regulation of the gonadotropin-gonadal axis. Pituitary $2001 ; 4: 87-92$.
6. Licinio J, Caglayan S, Ozata M, Yildiz BO, De Miranda PB, O'Kirwan F, et al Phenotypic effects of leptin replacement on morbid obesity, diabetes mellitus, hypogonadism, and behavior in leptin-deficient adults. PNAS 2004;101: 4531-6.

7. Ozata M, Ozdemir IC, Licinio J. Human leptin deficiency caused by a missense mutation: multiple endocrine defects, decreased sympathetic tone, and immune system dysfunction indicate new targets for leptin action, greater central than peripheral resistance to the effects of leptin, and spontaneous correction of leptin-mediated defects. J Clin Endocrinol Metab 1999;84: 3686-95.

8. Welt CK, Chan JL, Bullen J, Murphy R, Smith BS, Depaoli AM, et al. Recombinant human leptin in women with hypothalamic amenorrhea. N Engl J Med 2004;351 (10):987-97.

9. Zhang Y, Proença R, Maffei M, Baroni M, Leopold L, Friedman JM. Positional cloning of the mouse obese gene and its human homologue. Nature 1994;372(6505):425-32.

10. Carretero JIB, Barbancho L, Gonzalez MAV, Dacosta CV. Leptina: implicaciones fisiológicas y clínicas. An Med Interna 2001;18(3):152-60.

11. Houseknecht KL, Baile CA, Matteri RL, Spurlock ME. The biology of leptin: a review. J Animal Sci 1998;76:1405-20.

12. Mantzoros CS. The role of leptin in human obesity and disease: a review of current evidence. Ann Intern Med 1999;130:671-80.

13. Aggel-Leijssen DPC. Regulation of average $24 \mathrm{~h}$ human plasma leptin level: influence of exercise and physiological changes in energy balance. Int $\mathbf{J}$ Obes 1998;23:151-8.

14. Hulver MW, Houward JA. Plasma leptin and exercise. Sports Med 2003;33(7):473-82.

15. Negrão $A B$, Licinio J. Leptina: o diálogo entre adipócitos e neurônios. Arq Bras Endocrinol Metab 2000;44(3):205-14.

16. Thong FSL, Graham TE. Leptin and reproduction: Is it a critical link between adipose tissue, nutrition, and reproduction? Can J Appl Physiol 1999;24(4):317-36.

17. Huang L, Wang Z. Modulation of circulating leptin levels by its soluble receptor. J Biol Chem 2001;276(9):6343-9.

18. Hegyi K, Fulop K, Kovacs K, Toth S, Falus A. Leptin-induced signal transduction pathways. Cell Biol Int 2004;28:159-69.

19. Huang W, Cai L. Leptin: a multifunctional hormone. Cell Res 2000;10:81-92.

20. Yamashita T, Murakami T, Otani S, Kuwajima M, Shima K. Leptin receptor signal transduction: ObRa and ObRb of $\mathrm{fa}$ type. Biochem Biophys Res Commun 1998;246:752-9.

21. Chan JL, Bluher S, Yiannakouris N, Suchard MA, Kratzch J, Mantzoros CS. Regulation of circulating soluble leptin receptor levels by gender, adiposity, sex steroids and leptin. Diabetes 2002;51(7):2105-12.

22. Katzsch J, Lammert A, Bottner A, Seidel B, Mueller G, Thiery $\mathrm{J}$, et al. Circulating soluble leptin receptor and free leptin index during childhood, puberty and adolescence. J Clin Endocrinol Metab 2002;87:4587-94.

23. Mann DR, Johnson AOK, Gimpel T, Castracane VD. Changes in circulating leptin, leptin receptor, and gonadal hormones from infancy until advanced age in humans. $J$ Clin Endocrinol Metab 2003;88:3339-45.

24. Bouret SG, Simerly RB. Minireview: leptin and development of hypothalamic feeding circuits. Endocrinology 2004; 145:2621-6.

25. Dubuc GR, Phinney SD, Stern JS, Havel PJ. Changes of serum leptin and endocrine and metabolic parameters after 7 days of energy restriction in men and women. Metabolism 1998;47(4):429-34.

26. Pasman WJ, Westerterp-Plantenga MS, Saris WH. The effect of exercise training on leptin levels in obese males. Am J Physiol 1998;274(2 pt.1):E280-6.

27. Pisabarro R, Irrazábal E, Recalde A, Barrios E, Aguirre B, Loriente JMG, et al. Leptina: ¿un marcador de riesgo metabólico? Arch Med Int 1998;XX(3):113-5.

28. Garcia-Mayor RV, Andrade MA, Rios M, Lage M, Dieguez C, Casanueva FF. Serum leptin levels in normal children: relationship to age, gender, body mass index, pituitary-gonadal hormones and pubertal stage. J Clin Endocrinol Metab 1997:82:2849-55. 
29. Ahima RS, Flier JS. Adipose tissue as an endocrine organ. Trends Endocrinol Metab 2000;11:327-31.

30. Hickey MS, Houmard JA, Considine RV, Tyndall GL, Midgette JB, Gavigan KE, et al. Gender-dependent effects of exercise training on serum leptin levels in humans. Am J Physiol 1997;272(4 pt.1):562-6.

31. Campfield LA, Smith FJ, Burn P. The ob protein (leptin) pathway: a link between adipose tissue mass and central neural networks. Horm Metab 1996;28(12):619-32.

32. Woods SC, Gotoh K, Clegg DJ. Gender differences in the control of energy homeostasis. Exp Biol Med 2003;228:1175-80.

33. Munzberg $\mathrm{H}$, Myers MG. Molecular and anatomical determinants of central leptin resistance. Nat Neurosci 2005;8(5):566-70.

34. Whang ZW, Pan WT, Lee $Y$, et al. The role of leptin resistance in the lipid abnormalities of aging. FASEB J 2001;(15):10814.

35. Spiegelman BM, Flier JS. Adipogenesis and obesity: rounding out the big picture. Cell 1996;87:377-89.

36. Gullicksen PS, Flatt WP, Dean RG, Hartzell DL, Baile CA. Energy metabolism and expression of uncoupling proteins 1, 2 and 3 after 21 days of recovery from intracerebroventricular mouse leptin in rats. Physiol Behav 2002;75(4):473-82.

37. Ceddia RB, Willim Jr WN, Lima FB, Flandin P, Curi R, Giacobino JP. Leptin stimulates uncoupling protein-2 mRNA expression and Krebs cycle activity and inhibits lipid synthesis in isolated rat white adipocytes. Eur J Biochem 2000;267:5952-8.

38. Lord GM, Matarese G, Howard JK, Baker RJ, Bloom SR, Lechler RI. Leptin modulates the T-cell immune response and reverse starvation-induced immunosuppression. Nature 1998;394:897-901.

39. Nakata M, Yada T, Soejima N, Maruyama I. Leptin promotes aggregation of human platelets via the long form of its receptor. Diabetes 1999;48:426-9.

40. Ring BD, Scully S, Davis CR, Baker MB, Cullen MJ, Pelleymounter MA, et al. Systemically and topically administered leptin both accelerate wound healing in diabetic ob/ob mice. Endocrinology 2000;141:446-9.

41. Wang JL, Chinookoswong N, Scully S, Qi M, Shi ZQ. Differential effects of leptin in regulation of tissue glucose utilization in vivo. Endocrinology 1999;140(5):2117-24.

42. William WN, Ceddia RB, Curi R. Leptin controls the fate of fatty acids in isolated rat white adipocytes. J Endocrinol 2002;175:735-44.

43. Cohen P, Friedman JM. Leptin and the control of metabolism: role of stearoyl-coA desaturase-1 (SDC-1). J Nutr 2004; 134:2455S-63S.

44. Steinberg GR, Dyck DJ, Calles-Escandon J, Tandon NN, Luiken JJ, Glatz JF, et al. Chronic leptin administration decreases fatty acid uptake and fatty acid transporters in rat skeletal muscle. J Biol Chem 2002;277(11):8854-60.

45. Figlewicz DP. Adiposity signals and food rewars: expanding the CNS roles of insulin and leptin. Am J Physiol Regul Integr Comp Physiol 2003;284:R882-92.

46. Kraemer RR, Chu H, Castracane VD. Leptin and exercise. Exp Biol Med 2002;227:701-8.

47. Koutsari C, Karpe F, Humphreys SM, Frayn KN, Hardman AE. Plasma leptin is influenced by diet composition and exercise. Int J Obes Relat Metab Disord 2003;27(8):901-6.

48. Maughan R, Gleeson M, Greenhaff PL. Bioquímica do exercício e do treinamento. São Paulo: Manole, 2000.

49. Kimura M, Tatushi, N, Shiota T, Yashie F, Yamaushi H, Suzuki $M$, et al. Long-term exercise down regulates leptin receptor mRNA in the arcuate nucleus. Neuroreport 2004;15(4):713-6.

50. Ribeiro SML, Tirapegui J.Fator de crescimento semelhante à insulina-1: algumas relações com o crescimento corporal, tecidual, exercício físico e dieta. Cadernos de Nutrição 1996:10:30-47.

51. Ajuwona KM, Kuskea JL, Raglandb D, Adeolaa O, Hancockc $\mathrm{DL}$, Andersonc DB, et al. The regulation of IGF-1 by leptin in the pig is tissue specific and independent of changes in growth hormone. J Nutr Biochem 2003;14:522-30.
52. Farah SL, Thong CM, Terry EG. Plasma leptin in female athletes: relationship with body fat, reproductive, nutritional, and endocrine factors. J Appl Physiol 2000;88:2037-44.

53. Guyton CA, Hall EJ. Tratado de Fisiologia Médica. Rio de Janeiro: Guanabara Koogan, 1997.

54. Ainslie DA, Morris MJ, Wittert G, Turnbull H, Proietto J, Thorburn AW. Estrogen deficiency causes central leptin insensitivity and increased hypothalamic neuropeptide Y. Int J Obes 2001;25:1680-8.

55. Rickenlund A, Thorén M, Carlstrom K, Schoultz B, Hirschberg AL. Diurnal profiles of testosterone and pituitary hormones suggest different mechanisms for menstrual disturbances in endurance athletes. J Clin Endocrinol Metab 2004;89(2):702-7.

56. Andrico S, Alessandro G, Specchia C, Carolina PLF, Enrico S. Leptin in functional hypothalamic amenorrhea. Hum Reprod 2002;17(8):2043-8.

57. POSITIONS STATEMENTS. American College of Sports Medicine. The female athlete triad. Med Sci Sports Exerc1997;29(5):-I-ix.

58. Ahima RS. Body fat, leptin and hypothalamic amenorrhea (Perspective). N Engl J Med 2004;351(10):959-62.

59. Betty PL, Herbert C, McClean A. The female athlete triad: no pain, no gain? Clin Ped 2003;42:573-80.

60. Ahima RS, Prabakaran D, Mantzoros C, Qu D, Lowell B, Maratos-Flier JS, et al. Role of leptin in the neuroendocrine response to fasting. Nature 1996;382:250-2.

61. Tataranni PA, Monroe B, Dueck CA, Traub AS, Nicolson M, Manore MM, et al. Adiposity, plasma leptin concentration and reproductive function in active and sedentary females. Int $\mathbf{J}$ Obes 1997;21:818-21.

62. Ballauff A, Zeigler A, Emons G, Sturm G, Blum WF, Remschmidt $H$, et al. Serum leptin and gonadotropin levels in patients with anorexia nervosa during weight gain. Mol Psych 1999;4:71-5.

63. Laughlin GA, Yen SC. Hypoleptinemia in women athletes: Absence of a diurnal rhythm with amenorrhea. J Clin Endocrinol Metab 1998;82:318-21.

64. Loucks AB, Thuma JR. Luteinizing hormone pulsatility is disrupted at threshold of energy availability in regularly menstruating women. J Clin Endocrinol Metab 2003;88:297311.

65. Zerani M, Boiti C, Zampini D, Brecchia G, Dall'Aglio C, Ceccarelli $\mathrm{P}$, et al. $\mathrm{Ob}$ receptor in rabbit ovary and leptin in vitro regulation of corpora lutea. J Endocrinol 2004;183:279-88.

66. Chan JL, Heist K, DePaoli AM, Veldhuis JD, Mantzoros CS. The role of falling leptin levels in the neuroendocrine and metabolic adaptation to short-term starvation in healthy men. J Clin Invest 2003;111:1409-21.

67. Clarke IJ, Henry BA. Leptin and reproduction. Rev Reprod 1999;4:48-55.

68. Thong FSL, Mclean C, Grahan TE. Plasma leptin in female athletes: relationship with body fat, reproductive, nutritional and endocrine factors. J Appl Physiol 2000;88(6):2037-44.

69. Bluher S, Mantzoros CS. The role of leptin in regulating neuroendocrine function in humans. J Nutr 2004;134:2469S74S.

70. Conde H, Rueda A, Gracia B, Hormaza A, Agudelo JC. Edad Sexual en escolares de Cali, Colombia. Colomb Med 2003;34(2):69-76.

71. Chehab FF, Mounzih K, Lu R, Lim ME. Early onset of reproductive function in normal female mice treated with leptin. Science 1997; $275: 88-90$.

72. Magni P, Vettor R, Pagano C, Calcagno A, Beretta E, Messi E, et al. Expression of a leptin receptor in immortalized gonadotropin-releasing hormone-secreting neurons. Endocrinology 1999;140:1581-5.

73. Rondini TA, Baddini SP, Sousa LF, Bittencourt JC, Elias CF. Hypothalamic cocaine- and amphetamine-regulated transcript neurons project to areas expressing gonadotropin releasing hormone immunoreactivity and to the anteroventral periventricular nucleus in male and female rats. Neuroscience 2004; $125: 735-48$. 
74. Dudas B, Merchenthaler I. Three-dimensional representation of the neurotransmitter systems of the human hypothalamus: inputs of the gonadotrophin hormone-releasing hormone neuronal system. J Neuroendocrinol 2006;18:79-95.

75. Seminara SB, Messager S, Chatzidaki EE, Thresher RR, Acierno JR, Shagoury JK, et al. The GPR54 gene as a regulator of puberty. N Engl J Med 2003;349:1614-27.

76. Thompson EL, Patterson M, Murphy KG, Smith KL, Dhillo WS, Todd JF, et al. Central and peripheral administration of kisspeptin-10 stimulates the hypothalamic-pituitary-gonadal axis. J Neuroendocrinol 2004;16:850-8.

77. Smith JT, Cunningham MJ, Rissman EF, Clifton DK, Steiner RA. Regulation of kiss1 gene expression in the brain of the female mouse. Endocrinology 2005;146:3686-92.

78. Duggal PS, Van Der Hoek K, Milner CR, Ryan NK, Armstrong DT, Magoffin DA, et al. The in vivo and in vitro effect of exogenous leptin on ovulation in rat. Endocrinology 2000;141:1971-6.

79. Kraemer RR, Acevedo EO, Synovitz LB, Hebert EP, Gimpel, T, Castracane VD. Leptin and steroid hormone responses to exercise in adolescent female runners over a 7-week season. Eur J Appl Physiol 2001;86:85-91.

80. Schneider JE, Zhou D. Interactive effects of central leptin and peripheral fuel oxidation on estrous cyclicity. Am J Physiol 1999;277:R1020-4.

81. Hulver MW, Houward JA. Plasma leptin and exercise. Sports Med 2003;33(7):473-82.

82. Wiggins DL, Michael MD, Wiggins MED. The female athlete. Clin Sports Med 1997;16(4):593-612.

83. Loucks $A B$, Heath EM. Dietary restriction reduces luteinizing hormone (LH) pulse frequency during waking hours and increases LH pulse amplitude during sleep in young menstruating women. J Clin Endocrinol Metab 1994; 78(4):910-5.

84. Weimann E. Gender-related differences in elite gymnasts: the female athlete triad. J Appl Physiol 2002;92:2146-52.

85. Cunningham MJ, Clifton DK, Steiner RA. Leptin's actions on the reproductive axis: perspectives and mechanisms. Biol Reprod 1999;60:216-22.

86. Warren MP. Amenorrhea in endurance runners. J Clin Endocrinol Metab 1992;75(6):1393-7.

87. Warren MP, Voussoughian F, Geer EB, Hyle EP, Adberg CL, Ramos RH. Functional hypothalamic amenorrhea: hypoleptinemia and disordered eating. J Clin Endocrinol Metab 1999;84:873-7.

88. Rogero MM, Mendes RR, Tirapegui J. Aspectos neuroendócrinos e nutricionais em atletas com overtraining. Arq Bras Endocrinol Metab 2005;49(3):359-68.

89. Steinacker JM, Lorms W, Reissneiker S, Liu Y. New aspects of the hormone and cytokines response to training. Eur J Appl Physiol 2004;91(4):382-91.

90. Melo CM, Urasaki R, Rocca S, Ribeiro SML. Consumo de oxigênio pós-exercício (EPOC). Estudo comparativo em indivíduos jovens não treinados. FIEP Bull 2006;76(Special Ed.):615-8.

91. JOINT POSITION STATEMENTS. American College of Sports Medicine; American Dietetic Association; Dietitians of Canada. Nutrition and Athletic Performance. Med Sci Sports Exerc 2000;32(12):2130-45.

92. Lee RD, Nieman DC. Nutritional Assessment. St. Louis: Mosby, 1995.

93. Essig DA, Alderson NL, Ferguson MA, Bartoli WP, Durstine JL. Delayed effects of exercise on the plasma leptin concentration. Metabolism 2000;49(3):395-9.

94. Tuominen JA, Ebeling P, Laquier FW, Heiman ML, Stephens T, Koivisto VA. Serum leptin concentration and fuel homeostasis in healthy man. Eur J Clin Invest 1997;27(3):206-11.

95. Hilton LK, Loucks AB. Low energy availability, not exercise stress, suppresses the diurnal rhythm of leptin in healthy young women. Am J Physiol Endocrinol Metab 2000;278(1):E43-9.
96. Kraemer RR, Johnson LG, Haltom R, Kraemer GR, Hebert EP, Gimpel $T$, et al. Serum leptin concentration in response to acute exercise in postmenopausal women with and without hormone replacement therapy. Proc Soc Exp Biol Med 1999;221(3):171-7.

97. Duclos M, Corcuff B, Ruffie A, Roger P, Manier G. Rapid leptin decrease in immediate postexercise recovery. Clin Endocrinol 1999;50(3):337-42.

98. Torjman MC, Zafeiridis A, Paolone AM, Wilkerson C, Considine RV. Serum leptin during recovery following maximal incremental and prolonged exercise. J Sports Med 1999;20:444-50.

99. Leal-Cerro AA, Garcia-Luna P, Astorga R, Parejo J, Peino R, Dieguez $C$, et al. Serum leptin levels in male marathon athletes before and after the marathon run. J Clin Endocrinol Metabolism 1998;83(7):2376-9.

100.Fisher JS, Van Pelt RE, Zinder O, Landt WM. Acute exercise effect on postabsorptive serum leptin. J Appl Physiol 2001; $91: 680-6$.

101.Landt M, Lawson GM, Helgeson JM, Davila-Roman VG, Ladenson JH, Jaffe AS, et al. Prolonged exercise decrease serum leptin concentrations. Metabolism 2000;46:1109-12.

102. Franks PW, Farooqi IS, Luan J, Wong MY, Halsall I, O'Rahilly $S$, et al. Does physical activity energy expenditure explain the between-individual variation in plasma leptin concentrations after adjusting for differences in body composition? J Clin Endocrinol Metab 2003;88(7):3258-63.

103.Reseland JE, Anderssen SA, Solvoll K, Hjermann I, Urdal P, Holme I, et al. Effect of long-term in diet and exercise on plasma leptin concentrations. Am J Clin Nutr 2001;73:240-5.

104.Perusse L, Collier G, Gagnon J, Leon AS, Rao DC, Skinner JS, et al. Acute and chronic effects of exercise on leptin levels in humans. J Appl Physiol 1997;83(1):5-10.

105.Gutin B, Ramsey L, Barbeau P, Cannady W, Ferguson M, Litaker M, et al. Plasma leptin concentrations in obese children: changes during 4-mo periods with and without physical training. Am J Clin Nutr 1999;69(3):388-94.

106.Okazaki T, Himeno E, Manri H, Ogata H, Ikeda M. Effects of mild aerobic exercise and mild hypocaloric diet on plasma leptin in sedentary females. Clin Exp Pharmacol Physiol 1999;26:415-20.

107.Ryan AS, Pratley RE, Goldberg AP. Changes in plasma leptin and insulin action with resistive training in postmenopausal females. Int J Obes Relat Metab Disord 2000;24:27-32.

108.Zafeiridis A, Smilios IR, Considine V, Tokmakidis SP. Serum leptin responses after acute resistance exercise protocols. J Appl Physiol 2003;94:591-7.

109.Gippini A, Mato A, Peino R, Lage M, Dieguez C, Casanueva FF. Effect of resistance exercise (body building) training on serum leptin levels in young men. Implications for relationship between body mass index and serum leptin. J Endocrinol Invest 1999;22(11):824-81.

Endereço para correspondência:

Sandra Maria Lima Ribeiro

Coordenadoria de Pós Graduação

Universidade São Judas Tadeu

Rua Taquari 546

03166-000 São Paulo, SP

E-mail: smlribeiro@uol.com.br 